Article

\title{
Suppression of Superficial Microglial Activation by Spinal Cord Stimulation Attenuates Neuropathic Pain Following Sciatic Nerve Injury in Rats
}

\author{
Masamichi Shinoda $1, * \mathbb{D}$, Satoshi Fujita ${ }^{2}$, Shiori Sugawara ${ }^{3}$, Sayaka Asano ${ }^{4}$, Ryo Koyama ${ }^{5}$, \\ Shintaro Fujiwara ${ }^{6}$, Kumi Soma ${ }^{7}$, Takaaki Tamagawa ${ }^{5}$, Tomoyuki Matsui ${ }^{7}$, Daisuke Ikutame ${ }^{6}$, \\ Masatoshi Ando ${ }^{5}$, Ayaka Osada ${ }^{8}$, Yuki Kimura ${ }^{5}$, Kazutaka Kobayashi ${ }^{9}$, Takamitsu Yamamoto ${ }^{9}$, \\ Kuniko Kusama-Eguchi $^{10}$, Masayuki Kobayashi ${ }^{11}$, Yoshinori Hayashi ${ }^{1}$ (D) and Koichi Iwata ${ }^{1}$ \\ 1 Department of Physiology, Nihon University School of Dentistry, Tokyo 101-8310, Japan; \\ hayashi.yoshinori@nihon-u.ac.jp (Y.H.); iwata.kouichi@nihon-u.ac.jp (K.I.) \\ 2 Department of Biology, Nihon University School of Dentistry, Tokyo 101-8310, Japan; \\ fujita.satoshi@nihon-u.ac.jp \\ 3 Department of Psychosomatic Dentistry, Graduate School of Medical and Dental Science, Tokyo Medical and \\ Dental University, Tokyo 113-8510, Japan; 0629ompm@tmd.ac.jp \\ 4 Department of Oral Diagnostic Sciences, Nihon University School of Dentistry, Tokyo 101-8310, Japan; \\ bunny2838@gmail.com \\ 5 Department of Oral and Maxillofacial Surgery, Nihon University School of Dentistry, Tokyo 101-8310, Japan; \\ dery18014@g.nihon-u.ac.jp (R.K.); tamagawa.takaaki@nihon-u.ac.jp (T.T.); \\ dema17002@g.nihon-u.ac.jp (M.A.); deyu18010@g.nihon-u.ac.jp (Y.K.) \\ 6 Department of Complete Denture Prosthodontics, Nihon University School of Dentistry, Tokyo 101-8310, \\ Japan; desh19025@g.nihon-u.ac.jp (S.F.); deda17003@g.nihon-u.ac.jp (D.I.) \\ 7 Department of Pediatric Dentistry, Nihon University School of Dentistry, Tokyo 101-8310, Japan; \\ deku16016@g.nihon-u.ac.jp (K.S.); deto17027@g.nihon-u.ac.jp (T.M.) \\ 8 Department of Orthodontics, Nihon University School of Dentistry, Tokyo 101-8310, Japan; \\ deay18005@g.nihon-u.ac.jp \\ 9 Division of Neurosurgery, Department of Neurological Surgery, Nihon University School of Medicine, \\ Tokyo 173-8610, Japan; kobayashi.kazutaka@nihon-u.ac.jp (K.K.); yamamoto.takamitsu@nihon-u.ac.jp (T.Y.) \\ 10 Laboratory of Biochemistry, Nihon University School of Pharmacy, Chiba 274-8555, Japan; \\ kusama.kuniko@nihon-u.ac.jp \\ 11 Department of Pharmacology, Nihon University School of Dentistry, Tokyo 101-8310, Japan; \\ kobayashi.masayuki@nhon-u.ac.jp \\ * Correspondence: shinoda.masamichi@nihon-u.ac.jp; Tel.: +81-3-3219-8112
}

Received: 27 February 2020; Accepted: 27 March 2020; Published: 30 March 2020

check for updates

\begin{abstract}
We evaluated the mechanisms underlying the spinal cord stimulation (SCS)-induced analgesic effect on neuropathic pain following spared nerve injury (SNI). On day 3 after SNI, SCS was performed for $6 \mathrm{~h}$ by using electrodes paraspinally placed on the L4-S1 spinal cord. The effects of SCS and intraperitoneal minocycline administration on plantar mechanical sensitivity, microglial activation, and neuronal excitability in the L4 dorsal horn were assessed on day 3 after SNI. The somatosensory cortical responses to electrical stimulation of the hind paw on day 3 following SNI were examined by using in vivo optical imaging with a voltage-sensitive dye. On day 3 after SNI, plantar mechanical hypersensitivity and enhanced microglial activation were suppressed by minocycline or SCS, and L4 dorsal horn nociceptive neuronal hyperexcitability was suppressed by SCS. In vivo optical imaging also revealed that electrical stimulation of the hind paw-activated areas in the somatosensory cortex was decreased by SCS. The present findings suggest that SCS could suppress plantar SNI-induced neuropathic pain via inhibition of microglial activation in the L4 dorsal horn, which is involved in spinal neuronal hyperexcitability. SCS is likely to be a potential alternative and complementary medicine therapy to alleviate neuropathic pain following nerve injury.
\end{abstract}


Keywords: spinal cord stimulation; spared nerve injury; microglial activation; somatosensory cortex; in vivo optical imaging

\section{Introduction}

Neuropathic pain such as postherpetic neuralgia, post-stroke pain, and trigeminal neuralgia is known to occur as a result of peripheral and/or central neurological disturbances [1]. Neuropathic pain is also clinically typified by intractable non-noxious stimulation-induced pain and thought to be a direct result of a lesion or disease that affects the peripheral somatosensory system [2]. In clinical practice, spinal cord stimulation (SCS) has been well established as a safe and effective treatment of chronic, intractable pain including neuropathic pain [3,4]. Sciatic nerve injuries have been widely employed as an animal model of neuropathic pain, and SCS reportedly improves the intractable neuropathic pain following nerve injuries [5-9]. Presently, the prime analgesic effects of SCS involves the activation of the descending pain inhibitory system $[4,10]$.

Many studies have indicated that persistent mechanical hypersensitivity was induced in the hind paw following sciatic nerve injuries along with microglial cell accumulation in the spinal dorsal horn (SDH), and the suppression of microglial cell activation in the spinal cord significantly alleviated mechanical hypersensitivity [11-13]. In SDH, the increased Iba1 immunoreactivity that indicates the hyperactive states of microglia was reported to be detected as early as $20 \mathrm{~min}$, peaking on day 3, and remaining at a significant level on day 7 following peripheral nerve injury [14].

Nevertheless, it is still quite uncertain as to whether SCS will suppress SDH microglial activation and neuronal hyperexcitability following sciatic nerve injury. To evaluate the mechanisms underlying the SCS-induced modulation of neuropathic pain associated with sciatic nerve injury, we examined the effect of SCS on mechanical hypersensitivity and dorsal horn microglial activation, and assessed neuronal hyperexcitability in the dorsal horn following sciatic nerve injury.

Moreover, it is well known that pathological spinal nociceptive information originating from peripheral nerve injury is conveyed to supraspinal components of the central nervous system (CNS) such as the primary and secondary somatosensory cortices and limbic cortices [15]. The rewiring of the CNS circuitries and alterations of various molecular generation mechanisms occur in the CNS nociceptive pathways following peripheral nerve injury. These neuroplastic changes in the CNS nociceptive pathways are thought to be involved in the occurrence of persistent pain associated with peripheral nerve injury [16]. Thus, it is essential to determine whether SCS affects the neuronal activities in these upper CNS areas to evaluate the mechanisms underlying SCS-induced analgesic action on the persistent pain associated with peripheral nerve injury. We, therefore, performed in vivo optical imaging with a voltage-sensitive dye in the somatosensory cortex to elucidate whether SCS changes the spatiotemporal profiles of cortical responses to electrical stimulation of the hind paw following sciatic nerve injury.

\section{Results}

\subsection{SCS and Minocycline Depressed Plantar Mechanical Hypersensitivity Following SNI}

Paw withdrawal thresholds (PWTs) were remarkably decreased on day 3 following spared nerve injury (SNI) compared to naive animals in both SCS and sham-stimulation animals ( $p<0.001$ vs. naive; Figure 1a). SCS for six hours successively significantly recovered the decrement of PWT at $30 \mathrm{~min}$ post-SCS (post-sham stimulation $(n=6)$, SCS $(n=7), p=0.01)$. Moreover, PWT at $12 \mathrm{~h}$ after $6 \mathrm{~h}$ of successive SCS tended to be higher than that obtained in the post-sham stimulation group $(p=0.09)$. 

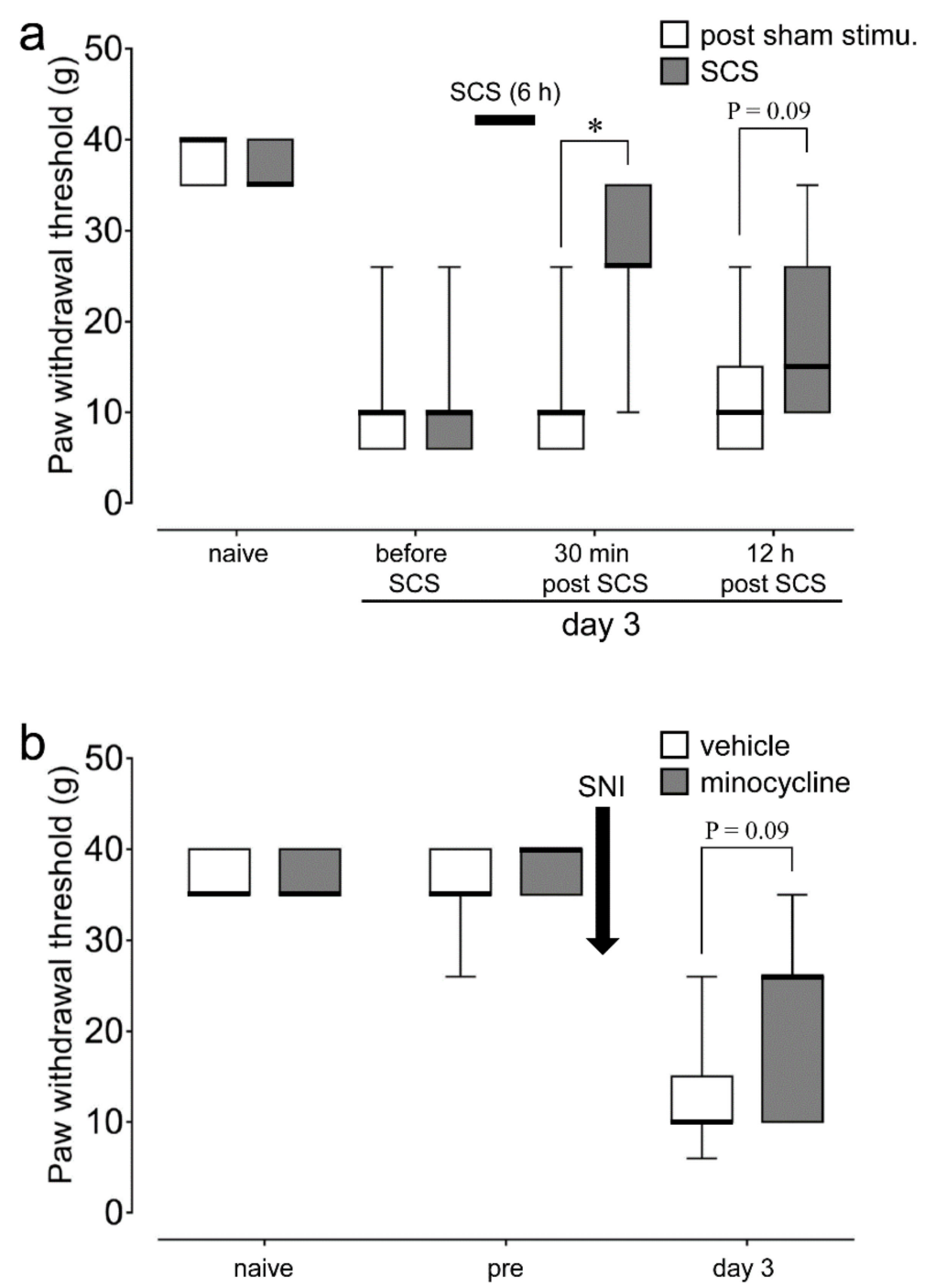

Figure 1. Effect of spinal cord stimulation (SCS) or minocycline on plantar mechanical hypersensitivity following spared nerve injury (SNI). (a) Paw withdrawal threshold (PWT) before SCS and at $30 \mathrm{~min}$ and $12 \mathrm{~h}$ after $6 \mathrm{~h}$ of successive SCS or sham stimulation on day 3 following SNI and PWT in naive rats. post-sham stimu.: post-sham stimulation. ${ }^{*} p<0.05$ vs. post-sham stimu. (Mann-Whitney $U$ test). (b) PWT before and on day 3 after SNI with once-daily intraperitoneal (i.p.) vehicle (saline) or minocycline $(30 \mathrm{mg} / \mathrm{kg} /$ day) administration and PWT in naive rats (Mann-Whitney $U$ test).

Successive intraperitoneal minocycline administration kept suppressing the SNI-induced decrement in PWT on day 3 following SNI, compared with successive intraperitoneal vehicle (saline) administration (vehicle $(n=7)$, SCS $(n=7), p=0.09)$ (Figure 1b). 


\subsection{Microglial and Astroglial Activation in the L4 Dorsal Horn}

The relative amount of Iba1 protein increased in the L4 SDH on day 3 following SNI $(n=4)$ compared with the control $(n=4)$ (Figure 2). Iba1-immunoreactive (IR) cells were observed in laminae II of the dorsal horn in the L4 spinal cord bilaterally on day 3 after SNI and $12 \mathrm{~h}$ after either SCS or sham-stimulation (Figure 3a). The morphology analysis of microglia was performed as previously described [17]. In the post-sham stimulation group, Iba1-IR cells changed their morphological features such as large soma and short processes on day 3 after SNI (Figure 3a, an inlet on the left). The ipsilateral density of Iba1-IR cells with large soma and short processes on day 3 after SNI with post-sham stimulation increased, and the increment in the ipsilateral density of Iba1-IR cells was significantly suppressed by SCS stimulation (post-sham $(n=3)$ : $12.8 \pm 1.3$; SCS $(n=3): 7.4 \pm 0.3, p=0.004$ ) (Figure $3 b$ ). On the other hand, there was no significant difference in the contralateral density of Iba1-IR cells on day 3 after SNI with SCS or post-sham stimulation.

Moreover, the ipsilateral increased density of Iba1-IR cells on day 3 after SNI with post-sham stimulation tended to be suppressed by intraperitoneal (i.p.) minocycline administration (vehicle (saline) $(n=3): 9.9 \pm 0.9$; minocycline $(n=3): 6.0 \pm 1.3, p=0.07$ ) (Figure $3 c$ ).

There was no significant difference in the ipsilateral and contralateral densities of glial fibrillary acidic protein (GFAP)-IR cells on day 3 after SNI with SCS or post-sham stimulation (Figure 4).

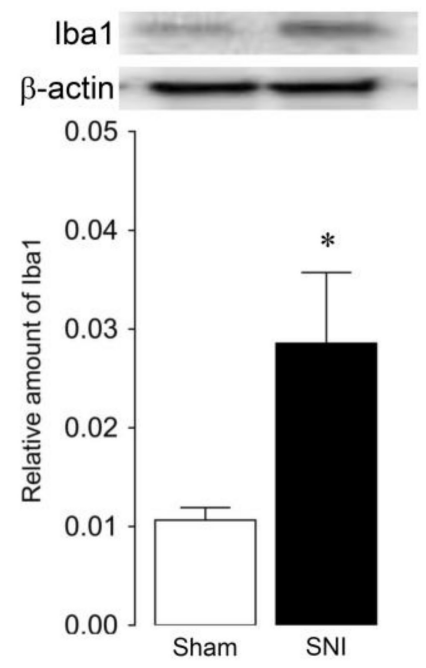

Figure 2. The relative amount of Iba1 protein in the ipsilateral L 4 dorsal horn on day 3 following SNI. Error bars indicate standard error of the mean (SEM). ${ }^{*} p<0.05$ sham. (Student's $t$-test). 

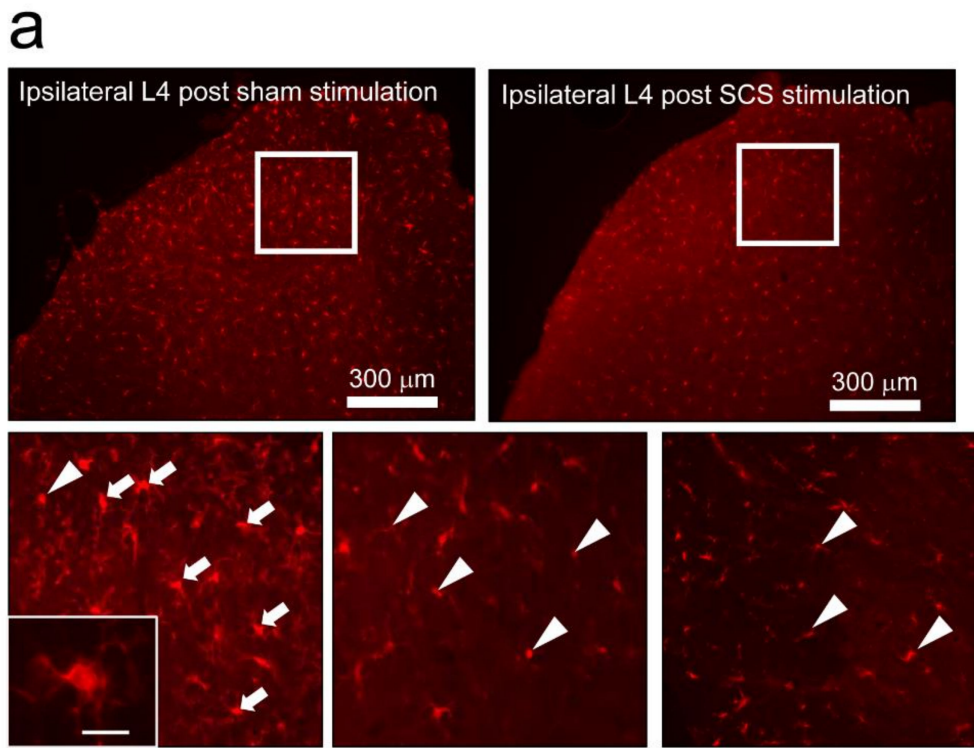

post sham stimu.

post SCS

post sham stimu.

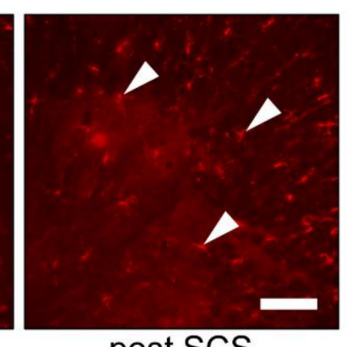

ipsilateral

\section{contralateral}

b

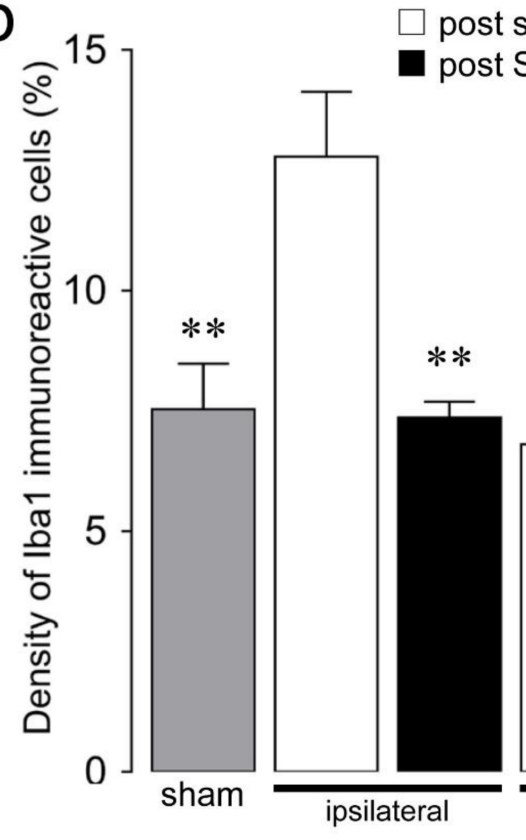

post sham stimu.

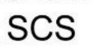

$* *$

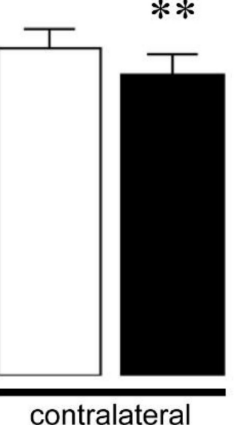

C

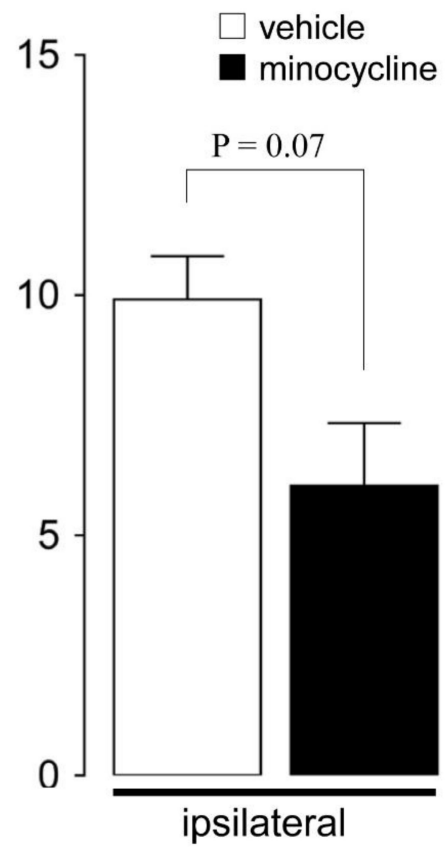

Figure 3. Changes in the L4 dorsal horn microglial activation on day 3 following SNI depending on SCS. (a) Iba1-immunoreactive (IR) cells in the bilateral L4 dorsal horn on day 3 following SNI with SCS or sham stimulation. White frame indicates the density analysis area. Arrows indicate activated Iba1-IR cells. Arrowhead indicates non-activated Iba1-IR cells. Scale bar: $100 \mu \mathrm{m}$. Inlet in (a) low and high magnification fluorescence micrograph of the activated Iba1-IR cells. Scale bar: $50 \mu \mathrm{m}$. (b) The bilateral density of Iba1-IR cells in the L4 dorsal horn on day 3 after SNI with SCS or sham stimulation, and in sham-injured rat-treated sham stimulation. Error bars indicate SEM. ${ }^{* *} p<0.01$ vs. post-sham stimulation (one-way ANOVA with Tukey's multiple-comparison test). (c) The ipsilateral density of Iba1-IR cells in the L4 dorsal horn on day 3 after SNI with once-daily i.p. vehicle (saline) or minocycline $(30 \mathrm{mg} / \mathrm{kg} /$ day) administration. Error bars indicate SEM. (Student's $t$-test). 

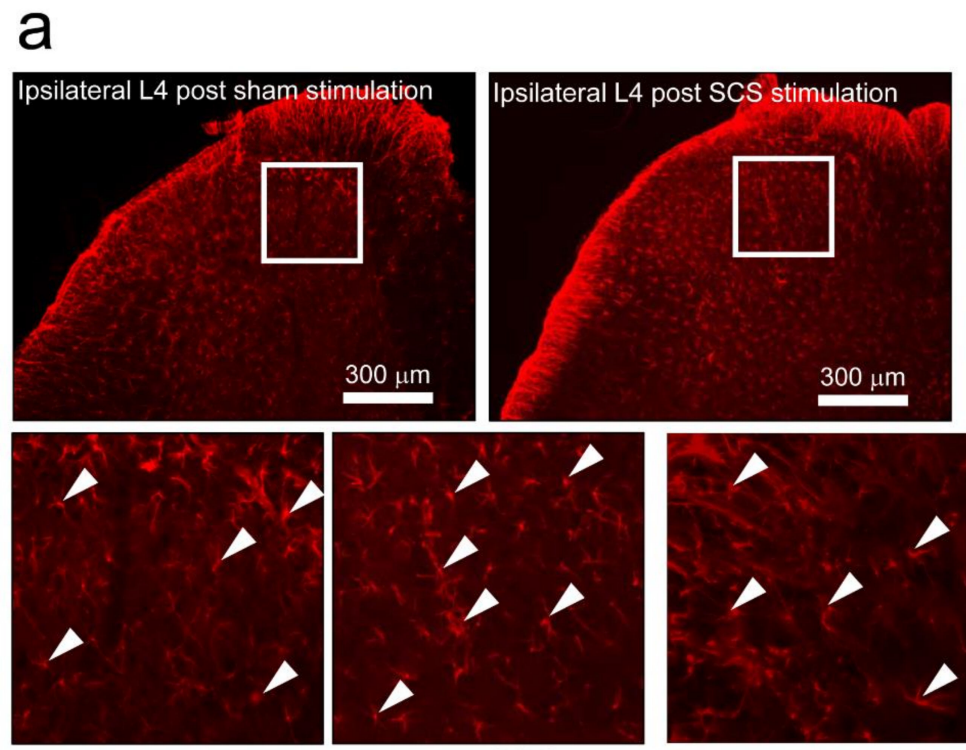

post sham stimu.

$$
\text { post SCS }
$$
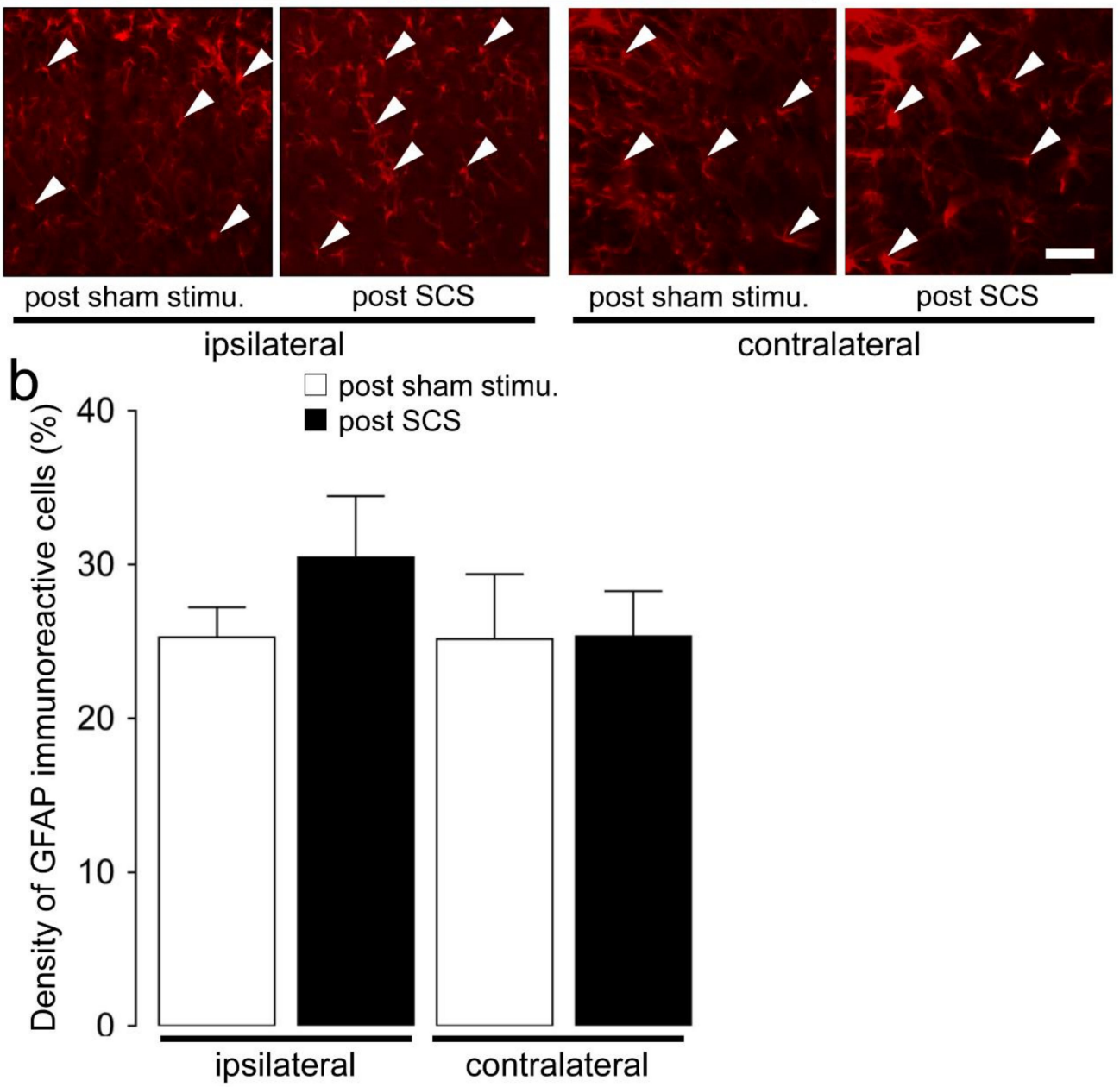

Figure 4. Changes in the L4 dorsal horn astroglial activation on day 3 following SNI depending on SCS. (a) Glial fibrillary acidic protein (GFAP)-IR cells in the bilateral L4 dorsal horn on day 3 following SNI with SCS or sham stimulation. Arrows indicate activated GFAP-IR cells. Scale bar: $100 \mu \mathrm{m}$. (b). The bilateral density of GFAP-IR cells in the L4 dorsal horn on day 3 after SNI with SCS or sham stimulation. Error bars indicate SEM.

\subsection{Effect of SCS on L4-S1 Nociceptive Neuronal Activity Following SNI}

Wide dynamic range (WDR) neurons in laminae II of L4-5 SDH showed responses to non-noxious and noxious mechanical stimulation of the hind paw (post-sham stimulation: six WDR neurons from two rats; post-SCS stimulation: five WDR neurons from three rats, Figure 5a). The mean number of spikes to $26 \mathrm{~g}$ (post-sham stimulation: $17.3 \pm 4.6$; post-SCS stimulation: $18.2 \pm 0.9, p=0.25$ ) and $60 \mathrm{~g}$ (post-sham stimulation: $28.6 \pm 4.9$; post-SCS stimulation: $48.2 \pm 0.9, p=0.006$ ) mechanical stimuli were significantly smaller in SNI rats with post-SCS stimulation compared with those in post-sham stimulation. 
a
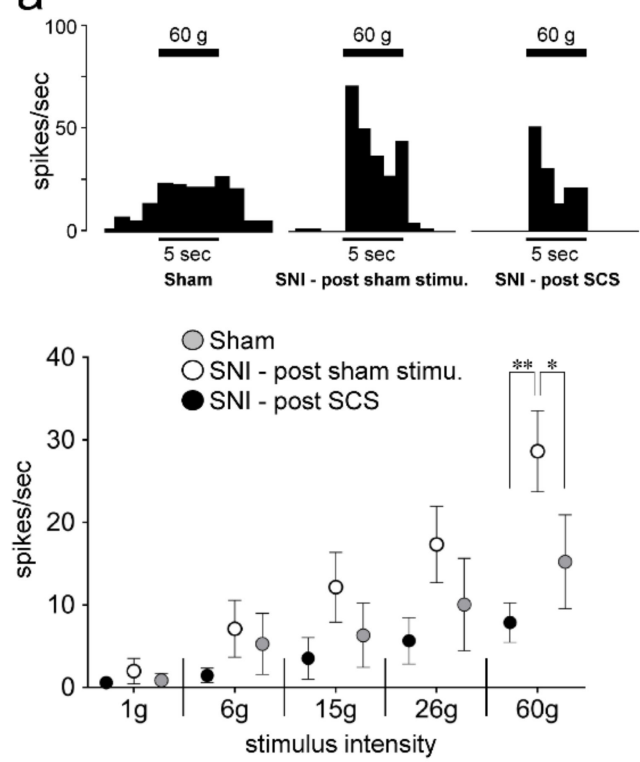

b
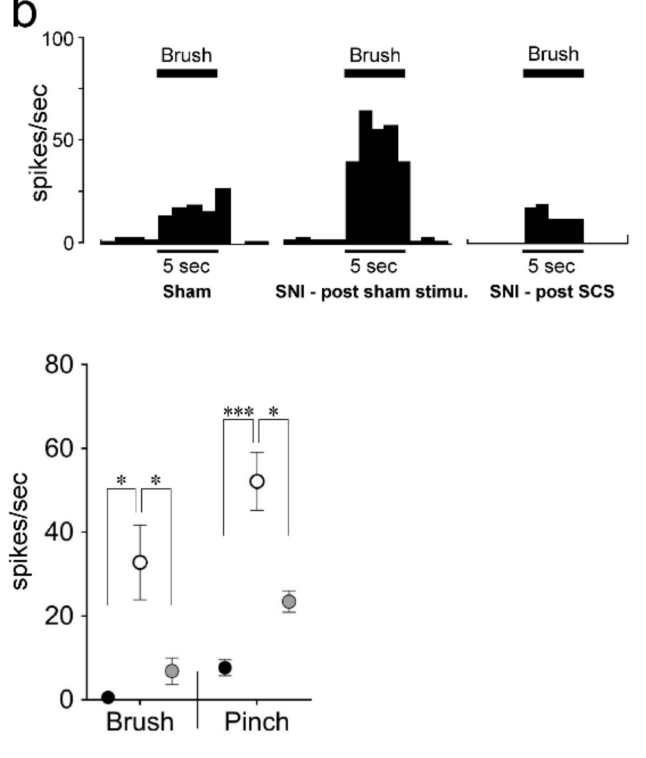

Figure 5. The effect of SCS on mechanical-evoked responses of wide dynamic range (WDR) neurons in lamina II of the dorsal horn in L4-S1 on day 3 following SNI with SCS or sham stimulation. The raw traces of WDR neurons responses and the frequency of WDR neuronal spikes in response to mechanical stimuli by von Frey filament (a) and brush or pinch stimuli (b) on day 3 after SNI with SCS or sham stimulation. Error bars indicate SEM. ${ }^{*} p<0.05,{ }^{* *} p<0.01,{ }^{* * *} p<0.001$ vs. post-sham stimulation (two-way ANOVA with repeated measures followed by Bonferroni's multiple-comparison tests or Student's $t$-test).

Furthermore, the mean number of spikes to pinch stimuli (post-sham stimulation: $52.1 \pm 7.0$; post-SCS stimulation: $7.7 \pm 1.3, p=0.003$ ) and brush stimuli (post-sham stimulation: $32.8 \pm 8.9$; postSCS stimulation: $0.6 \pm 0.1, p=0.04$ ) were significantly smaller in SNI rats with post-SCS stimulation than in those receiving post-sham stimulation (Figure $5 b$ ).

\subsection{Cortical Responses to Electrical Stimulation of the Hind Paw}

In optical imaging experiments, we used rats that received SNI. In agreement with a previous study [18], response to stimulation of the contralateral hind paw (Figure $6 c, d$ ) was initiated and spread over the surrounding region that was caudal and medial to the region initially activated by stimulation of the contralateral forepaw in a control rat (Figure $6 a, b, g$ ). In a rat that received SCS, stimulation of the contralateral hind paw similarly induced a cortical response, but the activated area was relatively small (Figure 6e,f). These results suggest that the pathway from the contralateral hind paw to the somatosensory cortex was preserved in rats receiving sciatic nerve ligation either with or without SCS.

To assess the temporal kinetics of cortical excitation induced by hind paw stimulation, we set regions of interest (ROIs) in the initial responses. To evaluate evoked cortical excitation in intensity, duration, and both of intensity and duration, peak amplitude, duration above 7SD, and the sum of amplitude exceeding 7SD were compared, respectively. Although a trend of reductions of this temporal kinetics, except the peak amplitude in electrical stimulation at $5 \mathrm{~V}$, was observed in the application after SCS (Figure 6h), the differences were not significant. 
a forepaw (5 V) SCS (-)

$0 \mathrm{~ms} \quad 18 \mathrm{~ms}$

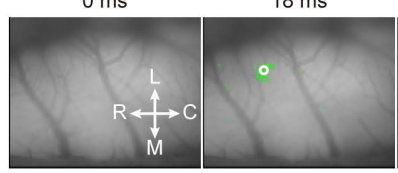

C hind paw (5 V) SCS (-)

$0 \mathrm{~ms}$

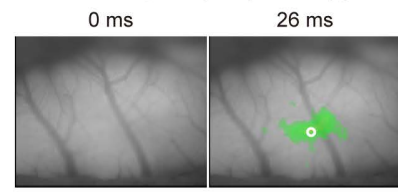

e hind paw (5 V) ScS (+)

$0 \mathrm{~ms}$

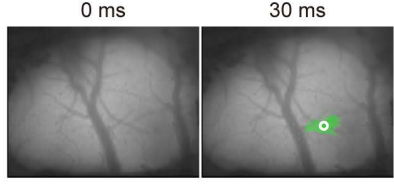
g forepaw (5 V)

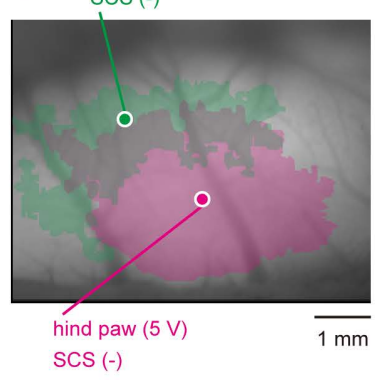

i $\quad$ hindpaw (5 V)

$\operatorname{SCS}(-)$

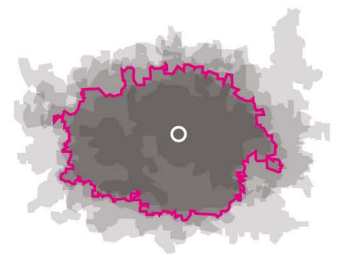

$22 \mathrm{~ms}$

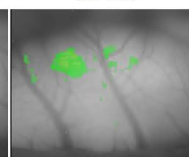

$26 \mathrm{~ms}$

$46 \mathrm{~ms}$
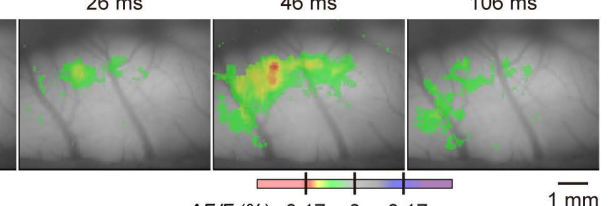

$\Delta F / F(\%) \quad 0.17 \quad 0 \quad-0.17$

$30 \mathrm{~ms}$

$34 \mathrm{~ms}$

$86 \mathrm{~ms}$

$166 \mathrm{~ms}$

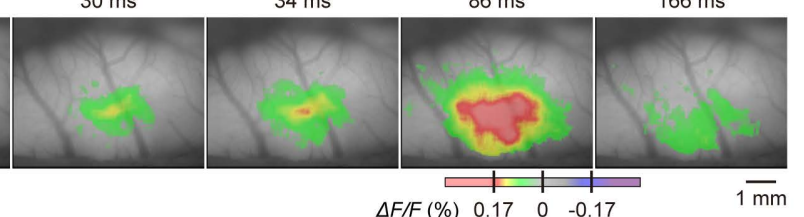

$\Delta F / F(\%) \quad 0.17 \quad 0 \quad-0.17$ $34 \mathrm{~ms}$ $38 \mathrm{~ms}$

$86 \mathrm{~ms}$ $166 \mathrm{~ms}$

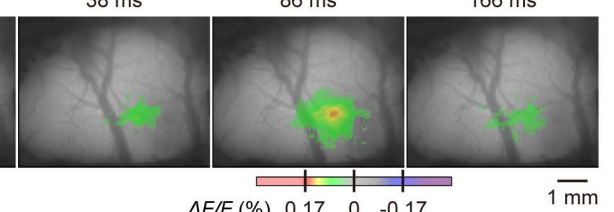

$\Delta F / F(\%) \quad 0.17 \quad 0 \quad-0.17$

h

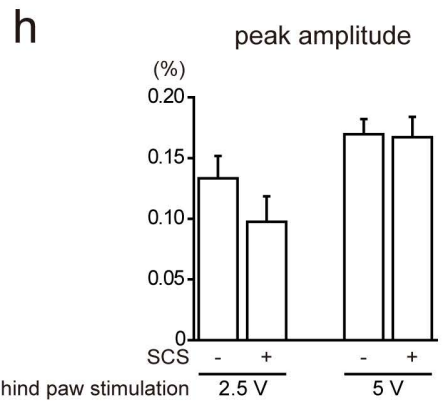

hind paw stimulation $\frac{-}{2.5 \mathrm{~V}}$

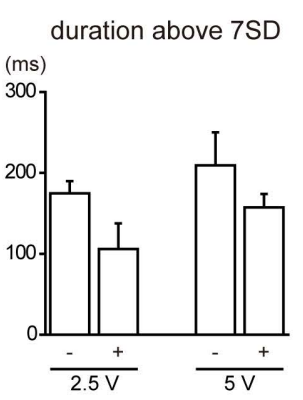

b

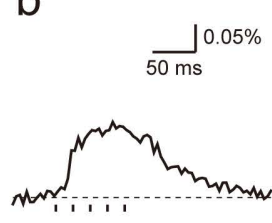

d

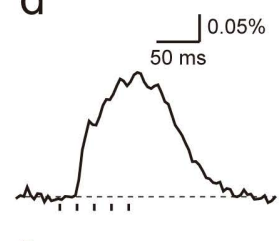

f

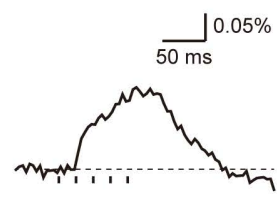

sum of amplitude

(\%)

exceeding $7 \mathrm{SD}$

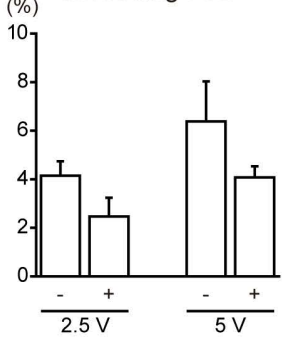

hindpaw (5 V)

SCS (+)

merged
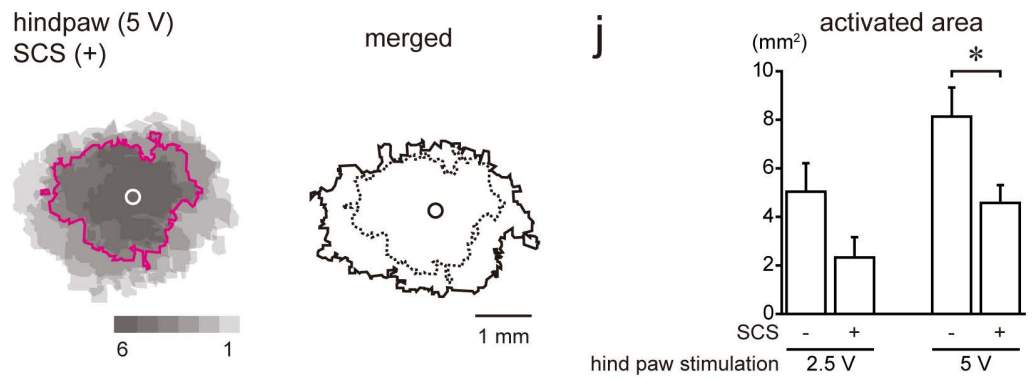

Figure 6. Responses in the right somatosensory cortex to electrical stimulation applied to the left forepaw and hindpaw in the absence (-) or presence (+) of SCS in the SNI model. An example of excitatory propagation (a) and the trace of optical signals $(\mathbf{b})$ during stimulation of forepaw in a rat without SCS. In (a), the amplitude of the optical signal $(\Delta F / F)$ is color-coded, and the time from the onset of the stimulation of the hindpaw is shown at the top of each panel. The trace in (b) is obtained in the region of interest (ROI) indicated by the white circle in (a). Vertical lines in (b) indicate the applied 5 voltage stimuli. C, caudal; L, lateral; M, medial; R, rostral. An example of excitatory propagation (c) and the trace of optical signals (d) during stimulation of the hind paw in a rat without SCS is shown. An example of excitatory propagation (e) and the trace of optical signals (f) during stimulation of the hind paw in a rat with SCS is shown. (g) The initial responses (circles) and activated areas (colored areas) in forepaw stimulation (green) and hind paw stimulation (magenta) without SCS are shown. Note that the region responding to hind paw stimulation was medial and caudal to the region responding to 
forepaw stimulation. tThe data shown in $(\mathbf{a}-\mathbf{d})$, and $(\mathbf{g})$ were obtained from the same animal. (h). Summary of peak amplitude, duration above 7SD, and the sum of amplitude exceeding 7SD obtained in the initial responses. Note that there are no significant differences between the control group $(n=6)$ and SCS group $(n=6)$. (i). Initial responses (circle) are aligned and activated areas in the control and SCS groups are superimposed. The number of overlapping responses is represented by the density of color. Magenta outlines indicate the overlapping areas in four of six rats. In the right panel, the outlines were merged. Solid and dashed lines indicate control and SCS groups, respectively. (j). Comparison of activated areas in response to hind paw stimulation without and with SCS. ${ }^{*} p<0.05$. (Student's $t$-test).

Next, we assessed areas activated by stimulation of the hind paw. Frames obtained at $95 \%$ peak amplitude were superimposed in Figure 6i, showing that the activated areas were suppressed by SCS. Comparison of the overlapping regions in $50 \%$ of the rats between the control and SCS groups revealed that SCS induced suppression in the activated area in a concentric manner (Figure 6i). The area of response to electrical stimulation $(5 \mathrm{~V})$ of the hind paw of animals that underwent SCS $(n=6 ; 4.6 \pm 0.8$ $\left.\mathrm{mm}^{2}\right)$ was significantly lower than that of animals that did not undergo SCS $\left(n=6 ; 8.1 \pm 1.3 \mathrm{~mm}^{2}\right.$; $p=0.044$, Student's $t$-test; Figure 6j).

\section{Discussion}

SNI elicited mechanical hypersensitivity in the ipsilateral hind paw for at least 3 days, and the mechanical hypersensitivity was depressed by $6 \mathrm{~h}$ of successive SCS at $30 \mathrm{~min}$ and $12 \mathrm{~h}$ post-SCS. Moreover, successive SCS must play an important role in SNI-induced mechanical hyperalgesia, because temporary SCS does not affect the mechanical hypersensitivity in the ipsilateral hind paw. At $12 \mathrm{~h}$ post-SCS, SNI-induced microglial activation in laminae II of the L4 dorsal horn were significantly depressed by $6 \mathrm{~h}$ successive SCS. Furthermore, intraperitoneal administration of minocycline, which is a pharmacological inhibitor of microglial activation, suppressed the SNI-induced microglial activation in the laminae II and the SNI-induced mechanical hypersensitivity on day 3 post-SCS was considered as an early development phase of chronic pain. Additionally, WDR neuronal excitability in laminae II caused by innoxious and noxious mechanical stimulation of the hind paw was also enhanced on day 3 after SNI, and the WDR neuronal hyperexcitability was recovered by successive intraperitoneal administration of minocycline. Some earlier studies propose that 14 days or more post-SNI is considered chronic neuropathic pain and much more closely mimics the clinical situation because it is conceivable that the central sensitization process becomes robust from around 2 weeks onwards $[16,19,20]$. However, the effects of SCS on the mechanical hypersensitivity associated with microglial activation in laminae II on day 3 post-SCS and its mechanism in this study might differ considerably compared with previous reports. Together, SCS potentially suppress SNI-induced mechanical hypersensitivity in the hind paw for a period of time via suppression of the WDR neuronal hyperexcitability produced by the inhibition of SNI-induced microglial activation in laminae II in the early development phase of chronic pain, although much further work is needed.

It is well known that the lamina II of the spinal dorsal horn plays a critical role in nociceptive transmission. The activated lamina II microglia that releases some cytokines causes the central sensitization of lamina II neurons and enhances spinal nociceptive transmission [21-23]. Therefore, we focused the changes in the microglial activation in laminae II by SCS. Recent studies demonstrate that microglial activation, which is characterized by increased expression of Iba1 and characteristic morphologic changes, occupies an important place in the enhancement of WDR neuronal excitability via various signaling molecules following peripheral nerve injury [24], resulting in pain hypersensitivity in the hind paw. For instance, peripheral nerve injury leads to the production and release of tumor necrosis factor $(\mathrm{TNF} \alpha)$ in microglia in SDH $[25,26]$. TNF $\alpha$ signaling in the transient receptor potential ion channel vanilloid 1-positive C-fiber central terminals of the sciatic nerve increases glutamate release, resulting in the enhancement of excitatory synaptic transmission in excitatory SDH interneurons in lamina II [27]. TNF $\alpha$ signaling also upregulates $N$-methyl-D-aspartic acid (NMDA) currents in lamina II excitatory spinal dorsal horn interneurons via the activation of the extracellular signal-regulated 
kinase and inhibits spontaneous firing in SDH gamma-aminobutyric acidic neurons, leading to spinal dorsal horn interneuronal hyperexcitability $[28,29]$. Additionally, endogenous interleukin- $1 \beta$ (IL-1 $\beta$ ) released from activated microglia also upregulates presynaptic NMDA receptor function in the neuropathic pain state [30]. Furthermore, the depression of inhibitory synaptic transmissions such as GABA and glycine-induced currents by IL-1 $\beta$ increases spinal neuronal excitability in lamina II [31]. Thus, the signaling of IL-1 $\beta$ released from activated microglia in the SDH might play a key role in central sensitization by enhancement of glutamate release from the central terminals of dorsal root ganglion neurons or postsynaptic NMDA currents by the phosphorylation of the NMDA receptor as well [31-33]. On the basis of these reports, we presume that the depression of SNI-induced mechanical hypersensitivity attributable to SCS occurs from the inhibition of microglial activation, which enhances the production of some signaling molecules after WDR neuronal hyperexcitability.

Thus far, nothing definite is known of the inhibitory mechanism of microglial activation by SCS. Microglia in the medullary dorsal horn are activated in orofacial pathological changes, increasing cytokine release from activated microglia before the enhancement of medullary neuronal excitability in WDR neurons [34]. Carrageenan-induced activation of microglia causes the production of proinflammatory cytokines in the L4-5 spinal cord [35]. Peripheral inflammation triggers cytokine production and release from activated microglia in the spinal cord and leads to inflammatory pain hypersensitivity [36]. On the basis of these previous reports, we suggest that SCS reduces the development of neuropathic pain associated with WDR neuronal hyperexcitability via any signaling molecules from activated microglia. On the other hand, there will be little involvement of astroglial activation in SCS-induced analgesia, as there was no significant difference in the astroglial activation after SNI with SCS or post-sham stimulation.

On the other hand, recent microarray and RNA-sequencing studies separately demonstrated an upregulation of immune response and activation marker of glial cells in the spinal cord by conventional SCS $[37,38]$. In this study, we defined the increased density of Iba1-IR cells with large soma and short processes as microglial activation, and its activation was significantly suppressed by SCS, although the above studies define upregulation of immune-related genes or cell membrane receptors transcription as microglial activation. The difference in definition of microglial activation might be the potential reasons for the discrepancy.

In the great majority of studies, the withdrawal threshold to mechanical stimulation of hind paw was used to assess the change in mechanical pain sensitivity under pathologic conditions such as cancer, nerve injury, or inflammation [39-41]. However, the reduction in the withdrawal threshold might be nothing more than an exaggerated escape reflex. Therefore, we observed cortical responses to stimulation of the hind paw by using in vivo optical imaging with a voltage-sensitive dye and assessed the spatiotemporal kinetics to investigate the effects of SCS. Although temporal kinetics indicated a trend of suppression of cortical response in the application of SCS, which might reflect the reduction of inputs to the somatosensory cortex, the differences were not significant. On the other hand, we found that the area activated by electrical stimulation of the hind paw was significantly decreased by SCS. The GABAergic system in the cerebral cortex plays a critical role in the regulation of the area of excitatory propagation [42]. The SCS might induce neuronal plastic changes in the GABAergic system of the somatosensory cortex. In a future study, additional experiments, such as the whole-cell patch clamp method in slice preparation, should be performed to address this hypothesis. Although the optical imaging with a voltage-sensitive dye is appropriate to assess the degree of neural excitation with a wide field of view, the signals made with excitatory and inhibitory neural activities are observed as a summation and cannot be distinguished [43]. In a future study, furthermore experiments, such as whole-cell patch-clamp method in slice preparation, should be performed to address mechanisms underlying the suppression in area of excitatory propagation.

Several studies suggest that SCS induces an analgesic effect on pain hypersensitivity in neuropathic pain models $[7,9,38,44]$, and a major clinical strength of SCS is that it can often dramatically reduce the intensity of neuropathic pain that other therapies have no effect on [45]. However, multiple studies have 
reported that the incidence of SCS complications is 30\% to $40 \%[45,46]$. The common hardware-related complications are lead failure and migration, then the common biological complications such as infection and pain over the implant $[47,48]$. Although pharmacological therapy does not require surgery such as the implantation of electrodes, continuous and close follow-up is always necessary to prevent side effects [49]. Clinically, appropriate treatment must be chosen for patients who suffer from the neuropathic pain.

Fourteen days post-lesion is considered chronic neuropathic pain in most pre-clinical studies where chronic neuropathic pain has been defined as that which persisted 14 days post-lesion; $30-40 \mathrm{~min}$ SCS stimulation paradigms have been tested in these studies [50-52]. On day 3 after peripheral nerve injury, the central sensitization process is not as robust as it is after 14 days. Furthermore, the effects and mechanism of SCS in this study might differ considerably. Therefore, due to differences in study design, it is impossible to directly compare our findings with those of clinical studies and further research is recommended.

\section{Materials and Methods}

\subsection{Animals}

This study was performed by using male Sprague-Dawley rats (6-weeks-old, $n=81$; Japan SLC, Shizuoka, Japan) that were bred well under appropriate conditions (room temperature: $23^{\circ} \mathrm{C}$; light-dark cycle: every $12 \mathrm{~h}$; ad libitum access to water and food). The Animal Experimentation Committee of Nihon University approved all procedures in the study (AP16D003-2 (9/23/2016), AP18DEN007-1 (4/27/2018)). The experiments were conducted by the guidelines issued by the International Association for the Study of Pain [53]. In all procedures, animal suffering and the number of animals were maximally reduced. Supplementary Figure S1 shows the schematics of the timeline of the experimental interventions.

\subsection{Spared Nerve Injury Model Preparation and SCS Electrode Implantation}

Rats were anesthetized with intraperitoneal (i.p.) butorphanol $(2.5 \mathrm{mg} / \mathrm{kg}$, Meiji Seika Pharma, Tokyo, Japan), medetomidine (0.375 mg/kg, Zenoaq, Koriyama, Japan), and midazolam ( $2.0 \mathrm{mg} / \mathrm{kg}$, Sandoz, Tokyo, Japan). The spared nerve injury (SNI) model was generated as previously described by Decosterd and Woolf [5]. Briefly, after pelvifemoral skin incision and muscle detachment, the common peroneal and tibial nerves were carefully isolated and dissected by scissors without any stress of the intact sural nerve.

In brief, back-skin incision and muscle detachment were performed, and the spinal column at the L1-4 levels was exposed by ablation of muscles attached to vertebrae with forceps under the deep anesthesia. After the SNI, the lead for SCS (TU216-007; Unique Medical, Tokyo, Japan) (Figure S1c) was paraspinally placed at the L4-S1 spinal cord without damaging the vertebrae or dura at all, with a cathode being installed in L4, and an anode being installed in S1. Therefore, the lead can be stimulating the L4-S1 spinal cord. The incised back-skin was closely sutured such that a part of the proximal end of the electrode was embedding subcutaneously. The incised skin and detached muscle were sutured using $4-0$ silk with the treatment of a local anesthetic ointment ( $2 \%$ xylocaine jelly; Aspen, Tokyo, Japan), and buprenorphine ( $0.9 \mu \mathrm{g}$, Otsuka, Tokyo, Japan) was administered subcutaneously for pain management.

\subsection{Plantar Mechanical Sensitivity}

Before (naive) and on day 3 after electrode implantation, rats were placed on a mesh-floor plastic box and allowed to adapt to their environments for $30 \mathrm{~min}$ before the testing. The plantar mechanical sensitivity was assessed using von Frey filaments pressed against the plantar surface in ascending order (pressures: 1.0, 1.4, 2.0, 4.0, 6.0, 8.0, 10, 15, 26, 30, 40, 50, and $60 \mathrm{~g}$ ). The paw withdrawal threshold (PWT) was determined as the lowest intensity evoking withdrawal response more than three times out 
of five stimuli (duration: $5 \mathrm{~s})$. For each trial, the filament was applied at $1 \mathrm{~s}$ intervals. A cutoff $(60 \mathrm{~g})$ was defined to avoid tissue injury. The interval between each mechanical stimulus was set at $>3$ min to avoid sensitization of the receptive field by frequent stimulus. The timing was based on previous studies [54-56]. Measurement of the PWT was performed under the same conditions and conducted in a randomized, experimenter-blinded design.

\subsection{SCS}

One hour after measurement of the PWT, an external neurostimulator (\# 37022, Medtronic, Dublin, Ireland) that can produce electrical pulses following the SCS protocol (\#8840, Medtronic) was connected with the proximal end of the electrode after cutting the 4-0 silk used to suture the incised skin, and pulling out the proximal end of electrode embedded subcutaneously under inhalation anesthesia with $2 \%$ isoflurane (Mylan, Southpointe, PA, USA). First, the motor threshold (MoT) was determined as the minimum amplitude of electrical stimulation (frequency: $4 \mathrm{~Hz}$, duration: $240 \mu \mathrm{s}$ ) that evokes mid-lower trunk or hind limb muscle contraction under inhalation anesthesia ( $2 \%$ isoflurane). After determination of MoT, SCS (frequency: $60 \mathrm{~Hz}$, duration: $240 \mu \mathrm{s}, 80 \% \mathrm{MoT}$ ) or sham stimulation $(0 \mathrm{~mA})$ was performed for $6 \mathrm{~h}$. The PWTs were measured at $30 \mathrm{~min}$ and $12 \mathrm{~h}$ after the completion of SCS as described above in a randomized, experimenter-blinded design. The timing of the recordings ( $30 \mathrm{~min}$ and $12 \mathrm{~h}$ post SCS) and SCS duration (6 h) were based on the pervious study [57].

\subsection{Effect of Minocycline Administration on Plantar Mechanical Sensitivity Following SNI}

A daily intraperitoneal minocycline hydrochloride (30 mg/kg/day, Merck, Darmstadt, Germany) or vehicle (saline) administration was performed for 4 days (day 0, 1, 2, and 3) after SNI. The dosage and administration method of minocycline were determined on the basis of previous studies $[44,58,59]$. On day 3 following SNI, the PWT was measured according to the behavioral testing method described above in a randomized (minocycline or vehicle), experimenter-blinded design.

\subsection{Immunohistochemistry}

At $12 \mathrm{~h}$ after the completion of SCS or sham stimulation, rats were perfused with $4 \%$ paraformaldehyde dissolved in $0.1 \mathrm{M}$ phosphate buffer followed by physiological saline under deep anesthesia using sodium pentobarbital (i.p., $50 \mathrm{mg} / \mathrm{kg}$ ). Sham-injured rat-treated sham stimulation were also perfused in a similar manner. The L4-S1 spinal cord was dissected and immersed in the above fixative for $24 \mathrm{~h}$. Then, spinal horizontal sections were cut with a freezing microtome (thickness: $30 \mu \mathrm{m}$ ) following immersion in $20 \%$ sucrose for $12 \mathrm{~h}$, and the three free-floating sections corresponding to L4 were collected in $0.01 \mathrm{M}$ phosphate-buffered saline (PBS). Because activated microglia showed an intense increase in Iba1 expression in various pathological states, we introduced Iba1 antibody for immunohistochemical analysis to evaluate whether microglial cells were activated [60]. Moreover, we introduced glial fibrillary acidic protein (GFAP) antibody for immunohistochemical analysis to evaluate whether astroglial cells were activated. The sections were incubated in goat anti-Iba1 polyclonal antiserum corresponding to the C-terminus of Iba1 (1:500, 019-19741; Wako, Osaka, Japan) or mouse anti-GFAP monoclonal antibody (1:500, MAB360; Merck, Darmstadt, Germany) in 0.3\% TritonX-100 in $0.01 \mathrm{M}$ PBS with $4 \%$ normal donkey serum overnight at $4{ }^{\circ} \mathrm{C}$. After rinsing with $0.01 \mathrm{M}$ PBS, the sections were incubated in Alexa Fluor 488 donkey anti-rabbit IgG diluted in 0.01M PBS (1:200, Merck) or Alexa Fluor 568 donkey anti-mouse IgG diluted in 0.01M PBS (1:200, Merck) for $2 \mathrm{~h}$ at $23^{\circ} \mathrm{C}$. After rinsing with $0.01 \mathrm{M}$ PBS, the sections were coverslipped in mounting medium (Thermo Fisher Scientific, Waltham, MA, USA), and Iba1-immunoreactive (IR) cells were examined by using fluorescence microscopy (Keyence BZ9000; Keyence, Osaka, Japan). The immunoreactivities of Iba-1 and GFAP showing an intensity twofold greater than the average background were considered positive for Iba-1 and GFAP immunoreactivity. The densities of Iba1-IR and GFAP-IR cells were measured in laminae II $\left(313.37 \times 313.37 \mu \mathrm{m}^{2}\right)$ of $\mathrm{L} 4 \mathrm{SDH}$ by using a computer-assisted imaging analysis system (ImageJ 1.37; National Institutes of Health, Bethesda, MD, USA). The densities of Iba1-IR and 
GFAP-IR cells were defined in the areas in laminae II $\left(313.37 \times 313.37 \mu \mathrm{m}^{2}\right)$ of L4 SDH occupied by the Iba1-immunoproducts in laminae II $\left(313.37 \times 313.37 \mu \mathrm{m}^{2}\right)$ of $\mathrm{L} 4 \mathrm{SDH}$. All immunohistochemical examinations were conducted under randomized conditions (ipsilateral or contralateral, SCS or sham stimulation) and the maximum degree of blinding.

\subsection{Western Blotting}

On day 3 after SNI or sham treatment, the rats were perfused with physiological saline under the i.p. deep anesthesia with the solution described above. Immediately, the L4 SDH ipsilateral to SNI or sham treatment was removed and homogenized in ice-cold lysis buffer $(137 \mathrm{mM} \mathrm{NaCl}$; $20 \mathrm{mM}$ Tris-HCl, pH 8.0; 1\% NP40; 10\% glycerol; $1 \mathrm{mM}$ phenylmethylsulfonyl fluoride; $10 \mu \mathrm{g} / \mathrm{mL}$ aprotinin; $1 \mathrm{~g} / \mathrm{mL}$ leupeptin; $0.05 \mathrm{mM}$ sodium vanadate). The homogenate was centrifuged, and the supernatants were extracted. The protein concentration of the supernatants was determined using a protein assay kit (Bio-Rad, Hercules, CA, USA). The supernatants were heat-denatured in Laemmli sample buffer solution (Bio-Rad), and the samples with protein adjusted to $30 \mu \mathrm{g}$ were subjected to electrophoresis on 10\% sodium dodecyl sulfate-polyacrylamide gel electrophoresis for protein separation. The samples were transferred to a polyvinylidene difluoride membrane (Trans-Blot Turbo Transfer Pack; Bio-Rad) utilizing Trans-Blot Turbo (Bio-Rad). The membrane was rinsed with Tris-buffered saline mixed with $0.1 \%$ Tween 20 (TBST, Bio-Rad) and incubated in 3\% bovine serum albumin (Bovogen, Essendon, Australia). The membrane was then incubated with rabbit anti-Iba1 polyclonal antibody (1:1,000; Wako, Tokyo, Japan) diluted in TBST with $3 \%$ BSA overnight at $4{ }^{\circ} \mathrm{C}$. Then, the horseradish peroxidase-conjugated rabbit anti-rabbit antibody (Jackson Immuno Research, West Grove, PA, USA) was incubated for $2 \mathrm{~h}$ at room temperature. Protein binding antibody was detected using Western Lightning ELC Pro (PerkinElmer, Waltham, MA, USA) and visualized using a ChemiDoc MP system (Bio-Rad). Using $\beta$-actin antibody (1:200; Santa Cruz, Santa Cruz, CA, USA) following removing bound protein by a stripping reagent (Thermo Fisher Scientific, Waltham, MA USA), the protein level was normalized to $\beta$-actin.

\subsection{Single Neuronal Recording}

At $12 \mathrm{~h}$ after completion of SCS or sham stimulation, the rats were strictly secured in the stereotaxic frame under the aforementioned deep anesthesia. The L4-5 SDH was exposed following a small laminectomy. Intravenous injection of pancuronium bromide $(0.6 \mathrm{mg} / \mathrm{kg} / \mathrm{h}$, Merck) was performed to produce muscular relaxation, and the rats were artificially ventilated. During the recording, end-tidal $\mathrm{CO}_{2}$ concentration $(3.5 \%$ to $4.5 \%)$, body temperature $\left(37^{\circ} \mathrm{C}\right)$, and heart rate remained steady under artificial respiration with oxygen $(2 \mathrm{~L} / \mathrm{min})$ and isoflurane $(2.0 \%)$. In this setting, enamel-coated tungsten microelectrodes (FHC, Bowdoin, ME, USA) were advanced into the lamina II in the L4-5 $\mathrm{SDH}$, and single neuronal activities were recorded. The graded mechanical stimuli were applied to the receptive field of the hind paw identified by gentle brush stimulus. The neuron that responded to both nonnoxious and noxious mechanical stimuli and increased its firing frequency as stimulus intensity increased was defined as wide dynamic range (WDR) neuron. The neuron that responded exclusively to noxious mechanical stimulation was defined as a nociceptive specific neuron [61]. WDR neurons responding to innocuous stimulation and, to a greater degree, noxious stimulation of the hind paw were examined in this study. After the identification of a WDR neuron, mechanical stimuli were applied to the hind paw following the recording of the neuron's background activity for $30 \mathrm{~s}$. For low-intensity mechanical stimulation of the neuronal mechanoreceptive field, graded stimuli with von Frey filaments $(1.0,6.0,15,26,60 \mathrm{~g})$ and brushing with a nylon hair brush were applied for $5 \mathrm{~s}$ at $10 \mathrm{~s}$ intervals. High-intensity (pinch) stimulation with pinch produced by a small arterial clip was also applied for $1 \mathrm{~min}$. The mechanical stimuli were applied 5 times for $5 \mathrm{~s}$ at a $1 \mathrm{~min}$ interval. This single neuronal activity was amplified using a differential amplifier (Nihon Koden, Tokyo, Japan) and stored in the microcomputer hard disk. Spikes were sorted, and spike frequencies were analyzed using the Spike II software (CED, Cambridge, UK). Neuronal responses were defined when the mean firing 
frequency was $>2$ standard deviations (SD) of the background activity, and the mean number of spikes elicited by mechanical stimuli applied for $5 \mathrm{~s}$ was examined at each stimulus intensity.

\subsection{In Vivo Optical Imaging With a Voltage-Sensitive Dye}

In optical imaging experiments, 12 rats were divided into two groups, that is, control group (rats received SNI but not SCS; $n=6$ ) and SCS group (rats received SNI and SCS; $n=6$ ). Optical imaging using a voltage-sensitive dye (RH-1691, Optical Imaging, New York, NY, USA) was performed as previously described [42,62-64]. Briefly, the rats received an atropine methyl bromide injection ( $5 \mathrm{mg} / \mathrm{kg}$, i.p.), were anesthetized with urethane (1.5 g/kg, i.p., Sigma-Aldrich, St. Louis, MO, USA), and were maintained at approximately at $37^{\circ} \mathrm{C}$ by using a rectal probe and a heating pad (BWT-100, Bio Research Center, Osaka, Japan). Additional urethane was administered depending on the toe pinch reflex, and the observation of cortical responses was performed under spontaneous breathing. Rats were fixed to a stereotaxic snout frame, and a craniotomy was performed to expose the right somatosensory cortex. We carefully resected the dura matter. After dura resection, RH-1691 $(1 \mathrm{mg} / \mathrm{mL})$ in $0.9 \%$ saline was applied to the cortical surface for $1 \mathrm{~h}$. Then, the cortical surface was rinsed with saline and covered with $1 \%$ agarose (Agarose Low EEO, Sigma-Aldrich) dissolved in Ringer's solution and a glass coverslip. Bipolar enamel-coated copper wire electrodes (diameter $=80 \mu \mathrm{m}$ ) were inserted into the ulnar side of the palm of the left forepaw and hind paw. To assess the cortical responses to the forepaw and hind paw stimulation, 5 voltage pulses ( $100 \mu$ s duration, 2.5 and $5 \mathrm{~V})$ at $50 \mathrm{~Hz}$ were applied using a stimulator unit (STG2008, Multi Channel Systems, Reutlingen, Germany). As was the case with the above-mentioned anesthesia with urethane, the electrical stimulation-induced spinal reflex was not observed visually. The cortical surface was illuminated through a $632 \mathrm{~nm}$ excitation filter with a dichroic mirror using a tungsten halogen lamp (CLS150XD, Leica Microsystems, Wetzlar, Germany). Fluorescent emission was captured through an absorption filter $(\lambda>650$-nm longpass, Andover, Salem, MA, USA). Changes in RH-1691 fluorescence intensity in response to the electrical stimulation of forepaw and hind paw were measured at $250 \mathrm{~Hz}$ for $1000 \mathrm{~ms}$, including a baseline period of $50 \mathrm{~ms}$, by using a CCD camera system (MiCAM02, Brainvision, Tokyo, Japan) mounted on a stereomicroscope (Leica Microsystems). The CCD camera had a $6.4 \times 4.8 \mathrm{~mm}^{2}$ imaging area $(184 \times 124$ pixels). To correct signals induced by acute bleaching of the dye, the fluorescence intensity without stimulation was subtracted from each recording. Electrical stimulation was performed with an interstimulus interval of $20 \mathrm{~s}$, and 40 images were averaged to improve the signal-to-noise ratio.

A software program (Brain Vision Analyzer; Brainvision) was used to process and analyze optical signals. Changes in the intensity of fluorescence $(\Delta F)$ of each pixel relative to the initial intensity of fluorescence $(F)$ were calculated $(\Delta F / F)$, and the ratio was processed with a spatial filter $(9 \times 9$ pixels $)$. A significant response was defined as a signal exceeding seven times the SD of the baseline period. A region of interest (ROI), a circle consisting of 77 pixels $\left(\approx 0.1 \mathrm{~mm}^{2}\right)$, was set on the basis of the initial response. Peak amplitude was defined as the maximum amplitude of optical response in the ROI. Durations above $7 \mathrm{SD}$ were defined as the duration of a significant response. To evaluate activated areas, we used the frames in which the optical signal first exceeded $95 \%$ of the maximum amplitude in the ROI [63].

\subsection{Statistical Analysis}

For comparisons of plantar mechanical sensitivity, Iba1 Western blotting and immunoreactivity, and lamina II neuronal activity, Mann-Whitney $U$ tests, one-way or two-way repeated-measures analysis of variance (ANOVA) followed by Tukey's or Bonferroni's multiple-comparison tests, and Student's $t$-tests were performed for statistical analyses by using Prism 7 (GraphPad Software, San Diego, CA, USA), appropriately. In a comparison of spatiotemporal kinetics, Student's $t$-test was used, following appropriate normality and equal variance tests. SigmaStat software (ver. 4.0, Systat Software, San Jose, CA, USA) was used for statistical analyses. In the comparison of plantar mechanical sensitivity, data were indicated as medians and 25th to 75 th percentiles, with the minimum 
and maximum values. Data for Iba1 immunoreactivity, lamina II neuronal activity, and spatiotemporal kinetics were expressed as the means \pm standard error (SEM). A $p$-value of less than 0.05 was considered statistically significant.

\section{Conclusions}

Overall, our data suggest that SCS could persistently suppress the microglial activation in laminae II following SNI, resulting in the depression of SNI-induced mechanical hypersensitivity in the hind paw relevant to the inhibition of SNI-induced WDR neuronal hyperexcitability. Moreover, electrical stimulation of hind paw-induced excitatory propagation in the somatosensory cortex was significantly decreased by SCS, suggesting that SCS decreased the pain hypersensitivity at the CNS level. Further studies are needed to elucidate the analgesic mechanisms of SCS in humans.

Supplementary Materials: Supplementary materials can be found at http://www.mdpi.com/1422-0067/21/7/2390/ s1. Figure S1. Time course of each experiments. Measurement of nociceptive mechanical sensitivity of following SCS (a) or following SCS with minocycline (b). The implanted electrode (c).

Author Contributions: Conceptualization, M.S., S.F., Y.H., M.K., K.K., T.Y., K.K.-E. and K.I.; methodology, S.S., S.A., R.K., S.F., T.T., M.A., K.S., T.M., A.O. and Y.K.; validation, M.S., D.I. and S.F.; formal analysis, M.S., S.F., Y.H., M.K., K.K., T.Y., K.K.-E. and K.I.; investigation, S.S., S.A., R.K., T.T., M.A., K.S., T.M., A.O. and Y.K.; data curation, M.S., S.F. and K.I.; writing—original draft preparation, M.S., S.F. and K.I.; writing—review and editing, M.S., S.F. and K.I.; visualization, M.S.; supervision, K.I. and M.K.; project administration, M.S. and S.F.; funding acquisition, M.S. and S.F. All authors have read and agreed to the published version of the manuscript.

Funding: This research was funded by the Japan Society for the Promotion of Science KAKENHI (19K10049 to M.S., and 16K11491 and 19K10064 to S.F., and 16K15783 and 16H05507 to M.K.), research grants from Sato and Uemura Funds from the Nihon University School of Dentistry, a grant from the Dental Research Center in Nihon University School of Dentistry, Nihon University Multidisciplinary Research Grant for (16-019 and 17-017), and MEXT-Supported Program for the Strategic Research Foundation at Private Universities (S1311021).

Acknowledgments: We would like to thank Editage (www.editage.jp) for English language editing.

Conflicts of Interest: The authors declare no conflict of interest.

\section{Abbreviations}

$\begin{array}{ll}\text { SCS } & \text { spinal cord stimulation } \\ \text { SNI } & \text { spared nerve injury } \\ \text { SDH } & \text { spinal dorsal horn } \\ \text { CNS } & \text { central nervous system } \\ \text { i.p. } & \text { intraperitoneal } \\ \text { PWT } & \text { paw withdrawal threshold } \\ \text { MoT } & \text { motor threshold } \\ \text { PBS } & \text { phosphate-buffered saline } \\ \text { GFAP } & \text { glial fibrillary acidic protein } \\ \text { IR } & \text { immunoreactive } \\ \text { WDR } & \text { wide dynamic range } \\ \text { SD } & \text { standard deviations } \\ \text { ROI } & \text { region of interest } \\ \text { ANOVA } & \text { analysis of variance } \\ \text { SEM } & \text { standard error of the mean } \\ \text { TNF } \alpha & \text { tumor necrosis factor alpha } \\ \text { NMDA } & N \text {-methyl-d-aspartic acid } \\ \text { IL-1 } \beta & \text { interleukin-1 beta }\end{array}$




\section{References}

1. Baron, R.; Binder, A.; Wasner, G. Neuropathic pain: Diagnosis, pathophysiological mechanisms, and treatment. Lancet Neurol. 2010, 9, 807-819. [CrossRef]

2. Sicras-Mainar, A.; Rejas-Gutierrez, J.; Perez-Paramo, M.; Navarro-Artieda, R. Cost of treatment of peripheral neuropathic pain with pregabalin or gabapentin in routine clinical practice: Impact of their loss of exclusivity. J. Eval. Clin. Pr. 2017, 23, 402-412. [CrossRef] [PubMed]

3. Al-Kaisy, A.; Van Buyten, J.P.; Amirdelfan, K.; Gliner, B.; Caraway, D.; Subbaroyan, J.; Rotte, A.; Kapural, L. Opioid-sparing effects of $10 \mathrm{kHz}$ spinal cord stimulation: A review of clinical evidence. Ann. N. Y. Acad. Sci. 2020, 1462, 53-64. [CrossRef] [PubMed]

4. Rock, A.K.; Truong, H.; Park, Y.L.; Pilitsis, J.G. Spinal Cord Stimulation. Neurosurg. Clin. N. Am. 2019, 30, 169-194. [CrossRef] [PubMed]

5. Decosterd, I.; Woolf, C.J. Spared nerve injury: An animal model of persistent peripheral neuropathic pain. Pain 2000, 87, 149-158. [CrossRef]

6. Gong, W.Y.; Johanek, L.M.; Sluka, K.A. A Comparison of the Effects of Burst and Tonic Spinal Cord Stimulation on Hyperalgesia and Physical Activity in an Animal Model of Neuropathic Pain. Anesth. Analg. 2016, 122, 1178-1185. [CrossRef]

7. Shechter, R.; Yang, F.; Xu, Q.; Cheong, Y.K.; He, S.Q.; Sdrulla, A.; Carteret, A.F.; Wacnik, P.W.; Dong, X.; Meyer, R.A.; et al. Conventional and kilohertz-frequency spinal cord stimulation produces intensityand frequency-dependent inhibition of mechanical hypersensitivity in a rat model of neuropathic pain. Anesthesiology 2013, 119, 422-432. [CrossRef]

8. Song, Z.; Viisanen, H.; Meyerson, B.A.; Pertovaara, A.; Linderoth, B. Efficacy of kilohertz-frequency and conventional spinal cord stimulation in rat models of different pain conditions. Neuromodulation 2014, 17, 226-234. [CrossRef]

9. Tilley, D.M.; Vallejo, R.; Kelley, C.A.; Benyamin, R.; Cedeno, D.L. A continuous spinal cord stimulation model attenuates pain-related behavior in vivo following induction of a peripheral nerve injury. Neuromodulation 2015, 18, 171-176. [CrossRef]

10. Crosby, N.D.; Weisshaar, C.L.; Smith, J.R.; Zeeman, M.E.; Goodman-Keiser, M.D.; Winkelstein, B.A. Burst and Tonic Spinal Cord Stimulation Differentially Activate GABAergic Mechanisms to Attenuate Pain in a Rat Model of Cervical Radiculopathy. IEEE Trans. Biomed. Eng. 2015, 62, 1604-1613. [CrossRef]

11. Chen, G.; Zhang, Y.Q.; Qadri, Y.J.; Serhan, C.N.; Ji, R.R. Microglia in Pain: Detrimental and Protective Roles in Pathogenesis and Resolution of Pain. Neuron 2018, 100, 1292-1311. [CrossRef] [PubMed]

12. Gui, Y.; Duan, S.; Xiao, L.; Tang, J.; Li, A. Bexarotent attenuated CCI-induced spinal neuroinflammation and neuropathic pain by targeting MKP-1. J. Pain 2019. [CrossRef] [PubMed]

13. Jones, M.; Wen, J.; Selvaraj, P.; Tanaka, M.; Moran, S.; Zhang, Y. Therapeutic Effect of the Substrate-Selective COX-2 Inhibitor IMMA in the Animal Model of Chronic Constriction Injury. Front. Pharm. 2018, 9, 1481. [CrossRef]

14. Chen, S.X.; Wang, S.K.; Yao, P.W.; Liao, G.J.; Na, X.D.; Li, Y.Y.; Zeng, W.A.; Liu, X.G.; Zang, Y. Early CALP2 expression and microglial activation are potential inducers of spinal IL-6 up-regulation and bilateral pain following motor nerve injury. J. Neurochem. 2018, 145, 154-169. [CrossRef] [PubMed]

15. Woller, S.A.; Eddinger, K.A.; Corr, M.; Yaksh, T.L. An overview of pathways encoding nociception. Clin. Exp. Rheumatol. 2018, 36, 172.

16. Takeuchi, Y.; Osaki, H.; Yagasaki, Y.; Katayama, Y.; Miyata, M. Afferent Fiber Remodeling in the Somatosensory Thalamus of Mice as a Neural Basis of Somatotopic Reorganization in the Brain and Ectopic Mechanical Hypersensitivity after Peripheral Sensory Nerve Injury. eNeuro 2017, 4. [CrossRef]

17. Morrison, H.W.; Filosa, J.A. A quantitative spatiotemporal analysis of microglia morphology during ischemic stroke and reperfusion. J. Neuroinflammation 2013, 10, 4. [CrossRef]

18. Morales-Botello, M.L.; Aguilar, J.; Foffani, G. Imaging the spatio-temporal dynamics of supragranular activity in the rat somatosensory cortex in response to stimulation of the paws. PLoS ONE 2012, 7, e40174. [CrossRef]

19. Nent, E.; Nozaki, C.; Schmole, A.C.; Otte, D.; Zimmer, A. CB2 receptor deletion on myeloid cells enhanced mechanical allodynia in a mouse model of neuropathic pain. Sci. Rep. 2019, 9, 7468. [CrossRef] 
20. Tsuda, M.; Mizokoshi, A.; Shigemoto-Mogami, Y.; Koizumi, S.; Inoue, K. Activation of p38 mitogen-activated protein kinase in spinal hyperactive microglia contributes to pain hypersensitivity following peripheral nerve injury. Glia 2004, 45, 89-95. [CrossRef]

21. Huang, C.Y.; Chen, Y.L.; Li, A.H.; Lu, J.C.; Wang, H.L. Minocycline, a microglial inhibitor, blocks spinal CCL2-induced heat hyperalgesia and augmentation of glutamatergic transmission in substantia gelatinosa neurons. J. Neuroinflammation 2014, 11, 7. [CrossRef] [PubMed]

22. Sonekatsu, M.; Taniguchi, W.; Yamanaka, M.; Nishio, N.; Tsutsui, S.; Yamada, H.; Yoshida, M.; Nakatsuka, T. Interferon-gamma potentiates NMDA receptor signaling in spinal dorsal horn neurons via microglia-neuron interaction. Mol. Pain 2016, 12. [CrossRef] [PubMed]

23. Chun, S.; Kwon, Y.B. The CCL2 elevation in primary afferent fibers produces zymosan-induced hyperalgesia through microglia-mediated neuronal activation in the spinal dorsal horn. Brain Res. Bull. 2019, 149, 53-59. [CrossRef] [PubMed]

24. Ji, R.R.; Berta, T.; Nedergaard, M. Glia and pain: Is chronic pain a gliopathy? Pain 2013, 154, S10-S28. [CrossRef] [PubMed]

25. Schafers, M.; Geis, C.; Svensson, C.I.; Luo, Z.D.; Sommer, C. Selective increase of tumour necrosis factor-alpha in injured and spared myelinated primary afferents after chronic constrictive injury of rat sciatic nerve. Eur. J. Neurosci. 2003, 17, 791-804. [CrossRef] [PubMed]

26. Xu, J.T.; Xin, W.J.; Zang, Y.; Wu, C.Y.; Liu, X.G. The role of tumor necrosis factor-alpha in the neuropathic pain induced by Lumbar 5 ventral root transection in rat. Pain 2006, 123, 306-321. [CrossRef]

27. Park, C.K.; Lu, N.; Xu, Z.Z.; Liu, T.; Serhan, C.N.; Ji, R.R. Resolving TRPV1- and TNF-alpha-mediated spinal cord synaptic plasticity and inflammatory pain with neuroprotectin D1. J. Neurosci. 2011, 31, 15072-15085. [CrossRef]

28. Xu, Z.Z.; Zhang, L.; Liu, T.; Park, J.Y.; Berta, T.; Yang, R.; Serhan, C.N.; Ji, R.R. Resolvins RvE1 and RvD1 attenuate inflammatory pain via central and peripheral actions. Nat. Med. 2010, 16, 592-597. [CrossRef]

29. Zhang, H.; Nei, H.; Dougherty, P.M. A p38 mitogen-activated protein kinase-dependent mechanism of disinhibition in spinal synaptic transmission induced by tumor necrosis factor-alpha. J. Neurosci. 2010, 30, 12844-12855. [CrossRef]

30. Yan, X.; Weng, H.R. Endogenous interleukin-1beta in neuropathic rats enhances glutamate release from the primary afferents in the spinal dorsal horn through coupling with presynaptic N-methyl-D-aspartic acid receptors. J. Biol. Chem. 2013, 288, 30544-30557. [CrossRef]

31. Kawasaki, Y.; Zhang, L.; Cheng, J.K.; Ji, R.R. Cytokine mechanisms of central sensitization: Distinct and overlapping role of interleukin-1beta, interleukin-6, and tumor necrosis factor-alpha in regulating synaptic and neuronal activity in the superficial spinal cord. J. Neurosci. 2008, 28, 5189-5194. [CrossRef] [PubMed]

32. Zhang, R.X.; Li, A.; Liu, B.; Wang, L.; Ren, K.; Zhang, H.; Berman, B.M.; Lao, L. IL-1ra alleviates inflammatory hyperalgesia through preventing phosphorylation of NMDA receptor NR-1 subunit in rats. Pain 2008, 135, 232-239. [CrossRef] [PubMed]

33. Ren, K.; Dubner, R. Interactions between the immune and nervous systems in pain. Nat. Med. 2010, 16, 1267-1276. [CrossRef] [PubMed]

34. Kiyomoto, M.; Shinoda, M.; Honda, K.; Nakaya, Y.; Dezawa, K.; Katagiri, A.; Kamakura, S.; Inoue, T.; Iwata, K. p38 phosphorylation in medullary microglia mediates ectopic orofacial inflammatory pain in rats. Mol. Pain 2015, 11, 48. [CrossRef]

35. Lu, Y.; Zhao, L.X.; Cao, D.L.; Gao, Y.J. Spinal injection of docosahexaenoic acid attenuates carrageenan-induced inflammatory pain through inhibition of microglia-mediated neuroinflammation in the spinal cord. Neuroscience 2013, 241, 22-31. [CrossRef]

36. Berta, T.; Park, C.K.; Xu, Z.Z.; Xie, R.G.; Liu, T.; Lu, N.; Liu, Y.C.; Ji, R.R. Extracellular caspase-6 drives murine inflammatory pain via microglial TNF-alpha secretion. J. Clin. Invest. 2014, 124, 1173-1186. [CrossRef]

37. Stephens, K.E.; Chen, Z.; Sivanesan, E.; Raja, S.N.; Linderoth, B.; Taverna, S.D.; Guan, Y. RNA-seq of spinal cord from nerve-injured rats after spinal cord stimulation. Mol. Pain 2018, 14. [CrossRef]

38. Vallejo, R.; Tilley, D.M.; Cedeno, D.L.; Kelley, C.A.; DeMaegd, M.; Benyamin, R. Genomics of the Effect of Spinal Cord Stimulation on an Animal Model of Neuropathic Pain. Neuromodulation 2016, 19, 576-586. [CrossRef]

39. Shinoda, M.; Ogino, A.; Ozaki, N.; Urano, H.; Hironaka, K.; Yasui, M.; Sugiura, Y. Involvement of TRPV1 in nociceptive behavior in a rat model of cancer pain. J. Pain 2008, 9, 687-699. [CrossRef] 
40. Asai, H.; Ozaki, N.; Shinoda, M.; Nagamine, K.; Tohnai, I.; Ueda, M.; Sugiura, Y. Heat and mechanical hyperalgesia in mice model of cancer pain. Pain 2005, 117, 19-29. [CrossRef]

41. Ma, H.; Yao, C.; Ma, P.; Zhou, J.; Gong, S.; Tao, J.; Yu, X.M.; Jiang, X. Src activation in the hypothalamic arcuate nucleus may play an important role in pain hypersensitivity. Sci. Rep. 2019, 9, 3827. [CrossRef] [PubMed]

42. Fujita, S.; Koshikawa, N.; Kobayashi, M. GABA(B) receptors accentuate neural excitation contrast in rat insular cortex. Neuroscience 2011, 199, 259-271. [CrossRef] [PubMed]

43. Chemla, S.; Chavane, F. Voltage-sensitive dye imaging: Technique review and models. J. Physiol. Paris 2010, 104, 40-50. [CrossRef] [PubMed]

44. Zhang, X.; Wang, J.; Yu, T.; Du, D.; Jiang, W. Minocycline can delay the development of morphine tolerance, but cannot reverse existing tolerance in the maintenance period of neuropathic pain in rats. Clin. Exp. Pharm. Physiol. 2015, 42, 94-101. [CrossRef]

45. Kumar, K.; North, R.; Taylor, R.; Sculpher, M.; Van den Abeele, C.; Gehring, M.; Jacques, L.; Eldabe, S.; Meglio, M.; Molet, J.; et al. Spinal Cord Stimulation vs. Conventional Medical Management: A Prospective, Randomized, Controlled, Multicenter Study of Patients with Failed Back Surgery Syndrome (PROCESS Study). Neuromodulation 2005, 8, 213-218. [CrossRef]

46. Kumar, K.; Taylor, R.S.; Jacques, L.; Eldabe, S.; Meglio, M.; Molet, J.; Thomson, S.; O'Callaghan, J.; Eisenberg, E.; Milbouw, G.; et al. Spinal cord stimulation versus conventional medical management for neuropathic pain: A multicentre randomised controlled trial in patients with failed back surgery syndrome. Pain 2007, 132, 179-188. [CrossRef]

47. Turner, J.A.; Loeser, J.D.; Bell, K.G. Spinal cord stimulation for chronic low back pain: A systematic literature synthesis. Neurosurgery 1995, 37, 1088-1095. [CrossRef]

48. Kumar, K.; Wilson, J.R.; Taylor, R.S.; Gupta, S. Complications of spinal cord stimulation, suggestions to improve outcome, and financial impact. J. Neurosurg. Spine 2006, 5, 191-203. [CrossRef]

49. Widerstrom-Noga, E. Neuropathic Pain and Spinal Cord Injury: Phenotypes and Pharmacological Management. Drugs 2017, 77, 967-984. [CrossRef]

50. Dombovy-Johnson, M.L.; Hunt, C.L.; Morrow, M.M.; Lamer, T.J.; Pittelkow, T.P. Current Evidence Lacking to Guide Clinical Practice for Spinal Cord Stimulation in the Treatment of Neuropathic Pain in Spinal Cord Injury: A Review of the Literature and a Proposal for Future Study. Pain Pr. 2020, 20, 325-335. [CrossRef]

51. Maheshwari, A.; Pope, J.E.; Deer, T.R.; Falowski, S. Advanced methods of spinal stimulation in the treatment of chronic pain: Pulse trains, waveforms, frequencies, targets, and feedback loops. Expert Rev. Med. Devices 2019, 16, 95-106. [CrossRef] [PubMed]

52. Sankarasubramanian, V.; Harte, S.E.; Chiravuri, S.; Harris, R.E.; Brummett, C.M.; Patil, P.G.; Clauw, D.J.; Lempka, S.F. Objective Measures to Characterize the Physiological Effects of Spinal Cord Stimulation in Neuropathic Pain: A Literature Review. Neuromodulation 2019, 22, 127-148. [CrossRef] [PubMed]

53. Zimmermann, M. Ethical guidelines for investigations of experimental pain in conscious animals. Pain 1983, 16, 109-110. [CrossRef]

54. Soma, K.; Shinoda, M.; Hayashi, Y.; Kanno, K.; Shirakwa, T.; Iwata, K. Involvement of TNFalpha in the enhancement of hypersensitivity in the adulthood-injured face associated with facial injury in infancy. Neurosci. Res. 2020. [CrossRef] [PubMed]

55. Sugawara, S.; Shinoda, M.; Hayashi, Y.; Saito, H.; Asano, S.; Kubo, A.; Shibuta, I.; Furukawa, A.; Toyofuku, A.; Iwata, K. Increase in IGF-1 Expression in the Injured Infraorbital Nerve and Possible Implications for Orofacial Neuropathic Pain. Int. J. Mol. Sci. 2019, 20. [CrossRef] [PubMed]

56. Kiyomoto, M.; Shinoda, M.; Okada-Ogawa, A.; Noma, N.; Shibuta, K.; Tsuboi, Y.; Sessle, B.J.; Imamura, Y.; Iwata, K. Fractalkine signaling in microglia contributes to ectopic orofacial pain following trapezius muscle inflammation. J. Neurosci. 2013, 33, 7667-7680. [CrossRef] [PubMed]

57. Gong, W.; Johanek, L.M.; Sluka, K.A. Spinal cord stimulation reduces mechanical hyperalgesia and restores physical activity levels in animals with noninflammatory muscle pain in a frequency-dependent manner. Anesth. Analg. 2014, 119, 186-195. [CrossRef]

58. Shibuta, K.; Suzuki, I.; Shinoda, M.; Tsuboi, Y.; Honda, K.; Shimizu, N.; Sessle, B.J.; Iwata, K. Organization of hyperactive microglial cells in trigeminal spinal subnucleus caudalis and upper cervical spinal cord associated with orofacial neuropathic pain. Brain Res. 2012, 1451, 74-86. [CrossRef]

59. Rojewska, E.; Korostynski, M.; Przewlocki, R.; Przewlocka, B.; Mika, J. Expression profiling of genes modulated by minocycline in a rat model of neuropathic pain. Mol. Pain 2014, 10, 47. [CrossRef] 
60. Inoue, K.; Tsuda, M. Microglia in neuropathic pain: Cellular and molecular mechanisms and therapeutic potential. Nat. Rev. Neurosci. 2018, 19, 138-152. [CrossRef]

61. Iwata, K.; Imai, T.; Tsuboi, Y.; Tashiro, A.; Ogawa, A.; Morimoto, T.; Masuda, Y.; Tachibana, Y.; Hu, J. Alteration of medullary dorsal horn neuronal activity following inferior alveolar nerve transection in rats. $J$. Neurophysiol. 2001, 86, 2868-2877. [CrossRef] [PubMed]

62. Fujita, S.; Kaneko, M.; Nakamura, H.; Kobayashi, M. Spatiotemporal Profiles of Proprioception Processed by the Masseter Muscle Spindles in Rat Cerebral Cortex: An Optical Imaging Study. Front. Neural Circuits 2017, 11, 4. [CrossRef] [PubMed]

63. Fujita, S.; Zama, M.; Kaneko, K.; Murayama, S.; Ohtani, S.; Usui, M.; Noma, D.; Tsuda, H.; Yamamoto, K.; Kobayashi, M. Menthol-induced facilitation of cerebrocortical excitatory propagation induced by air puff stimulation of the nasal cavity in the rat: An optical imaging study. Neurosci. Lett. 2018, 696, 87-92. [CrossRef] [PubMed]

64. Fujita, S.; Yamamoto, K.; Kobayashi, M. Trigeminal Nerve Transection-Induced Neuroplastic Changes in the Somatosensory and Insular Cortices in a Rat Ectopic Pain Model. eNeuro 2019, 6. [CrossRef]

(C) 2020 by the authors. Licensee MDPI, Basel, Switzerland. This article is an open access article distributed under the terms and conditions of the Creative Commons Attribution (CC BY) license (http://creativecommons.org/licenses/by/4.0/). 